\title{
Effects of tangential and radial velocity on fluid flow and heat transfer for flow through a pipe with twisted tape insert-laminar flow
}

\author{
PARAG CHAWARE ${ }^{1,2} \mathbb{D}$ and C M SEWATKAR ${ }^{1, *}$ \\ ${ }^{1}$ Department of Mechanical Engineering, College of Engineering Pune (Affiliated to SPPU, Pune), \\ Pune 411005, India \\ ${ }^{2}$ Department of Mechanical Engineering, Cummins College of Engineering for Women (Affiliated to SPPU, \\ Pune), Pune 411052, India \\ e-mail: cms.mech@coep.ac.in
}

MS received 1 July 2017; revised 9 December 2017; accepted 18 January 2018; published online 27 July 2018

\begin{abstract}
The present study reports the numerical analysis of fluid flow and heat transfer in a pipe with full length twisted tape insert. The investigation is carried out for five different twist ratios of 4, 5, 6, 8 and 10 at $100 \leq \operatorname{Re} \leq 1000$. The velocity field in terms of streamwise, tangential and radial velocity and temperature field are studied as a function of Reynolds number and twist ratio. The variation of friction factor and Nusselt number with Reynolds number for different twist ratios is also presented. The heat transfer enhancement due to insertion of twisted tape mainly comes from the tangential and radial components of velocities, which are regarded as secondary fluid motion. It is evident from the results that with increase in Reynolds number the axial convection increases. However, with the decrease in the twist ratio, the tangential and radial convection increases, leading to increased heat transfer. The secondary flow affects the thermal boundary layer inside the tube and increases the cross-flow mixing, which increases the heat transfer. The correlations for prediction of friction factor and Nusselt number based on the numerical data are also proposed.
\end{abstract}

Keywords. Twisted tape; heat transfer augmentation; tangential velocity; radial velocity.

\section{Introduction}

High cost and scarcity of energy have resulted in increased efforts aimed at producing more efficient heat exchangers. The efficiency of heat exchangers can be increased using heat transfer augmentation techniques. One of the most favourable heat transfer augmentation techniques is generating swirl flow by insertion of a twisted tape because the tape is inexpensive and can be easily employed to the existing system.

Twisted tapes are metallic strips twisted along their longitudinal axis at desired dimensions. Insertion of these tapes provides simple passive heat transfer augmentation by introducing the swirl to the flow and decreasing the thickness of the boundary layer. Twisted tape inserts force the fluid to follow a helical path rather than a straight one. This results in increased convective heat transfer coefficient between the tube inner wall and the fluid. The other reason for this increased heat transfer is the higher velocity in a direction other than streamwise direction. The twisted tape itself provides an additional heat transfer surface by acting as a fin. Twisted tapes have been widely investigated by many researchers since the twentieth century. Smithberg

*For correspondence and Landis [1] in their experimental study revealed that the twisted tape converts straight flow passage into two semicircular helical passages. The swirl produced by the flow alters the near-wall velocity and temperature profiles. These effects are predominantly responsible for heat transfer enhancement. The performance of the twisted tape in the laminar region is investigated both experimentally and numerically by Hong and Bergles [2]. They argued that the increase in secondary velocities and reduction in the thermal boundary layer are the reasons for the heat transfer enhancement. Date [3] reported that the tape fin effect is the key parameter in heat transfer enhancement. The heat transfer enhancement depends on the conductivity of the tape material. Empirical heat transfer and pressure drop correlations in common use for tubular flows with a conventional twist tape insert were generated by Manglik and Bergles [4] using Reynolds number and twisted ratio as the governing parameters. It is proposed that the twisted tape prohibits the transitional jump from laminar to turbulent flow. The monotonic transition from laminar to turbulent is achieved with the twisted tape. Agarwal and Rao [5] determined the influence of Prandtl number on friction factor and heat transfer rate in a tube with twisted tape inserts under constant wall temperature (heating and cooling) conditions. The effect of twist is more in the case of 
cooling than heating. The 'cold-wall' insulation effect is almost eliminated if twisted tape with small twist ratio is used for viscous fluids. Performance comparison of twisted tape insert and wire coil insert in the laminar and turbulent region was carried out by Wang and Sunden [6]. Their research concludes that tube insert technology is more effective in the laminar region than the turbulent region. In the laminar region, the heat transfer enhancement ratio is maximum up to $30 \%$ and in the turbulent region, it is up to $3.5 \%$. Experimental investigation of tubes fitted with single, twin and triple twisted tapes was carried out by Chang et al [7]. The results showed that effective range of Reynolds number for heat transfer augmentation increases with number of twisted tapes.

Klepper [8] used a short length twisted tape instead of full length and inferred that the pressure drop penalty can be reduced with the use of such arrangement. However, decaying swirl over the length reduces heat transfer enhancement. Saha et al [9, 10] and Saha and Dutta [11] investigated the arrangement of multiple short length twisted tapes. The performance of regularly spaced twisted tapes, which provide periodical swirl, mainly depends on the space ratio and the phase angle between two adjacent twisted tape elements. This arrangement can provide $40 \%$ less pressure drop than full length twisted tapes. Regularly spaced twisted tapes are often connected by a rod. The rod diameter affects the heat transfer and pressure drop. This is useful in the laminar region only. In the turbulent regime its performance is poor. Eiamsa-ard et al [12] also studied the regularly spaced twisted tapes and showed that the space ratio has to be less than unity to achieve large heat transfer rate. Numerical study of twisted tape performance was carried out by Saha and Date [13]. They observed that the axial velocity profile becomes flatter with decreasing twist ratio and increasing Reynolds number. Chiu and Jang [14] presented a numerical analysis of three types of inserts: longitudinal tape, longitudinal tape with holes and twisted tape insert. Their investigations show that the longitudinal tape and twisted tape offer good results and maximum area reduction is observed at the lowest twist ratio studied. Numerical simulation of swirling flow using 'loose-fitted' twisted tape is studied by Eiamsa-ard et al [15]. The closely fitted twisted tape shows better performance than that of the loose fit twisted tape. Rahimi et al [16] presented a comparison of three types of modified twisted tapes, with the classical twisted tape. The 'jagged' type of twisted tape shows maximum heat transfer and performance ratio. The turbulence intensity produced by the jagged tape and the vorticity at the jagged edges are also the key factors in producing the highest heat transfer among the types of tapes studied. Numerical simulation of edge fold twisted tape is carried out by Cui and Tian [17]. It is showed that the tape fin effect is the most significant parameter in modified twisted tape insert. Centre-cleared tape is investigated numerically by Guo et al [18]. It is inferred that cutting the central part of the tape is more significant than the boundary of tape as clearing the boundary weakens the swirl and increases the thickness of thermal boundary layer. This helps to weaken the temperature gradient, which in turn reduces the heat transfer augmentation. Thermal performance of the tape can be increased by 7-20\% by centrecleared tape. Extensive numerical study of heat transfer enhancement using twisted tape was carried out by Lin and Wang [19] for both uniform wall temperature (UWT) and uniform heat flux (UHF) conditions. The study mainly focuses on the effect of thermal contact resistance between tape and tube and the conduction of tape. It is concluded that the conduction in the tape is important in UWT conditions. In the case of twisted tapes in perfect fitness with the tube, heat transfer from the tape can reach up to more than $23 \%$ of overall heat transferred for UWT condition while only $3.2 \%$ of overall heat is transferred under UHF conditions. Heat transfer enhancement using secondary flow is strongly dependent on the thermal boundary conditions of the tube wall, the conduction in the tape and the intensity of secondary flow. The efficiency of heat transfer enhancement is better when UWT is enforced than when $\mathrm{UHF}$ is imposed, especially for the nonconducting tape cases.

Thus, it is noticed that the phenomenon of heat transfer enhancement using twisted tape is studied widely. The earlier numerical studies primarily focused on the effect of Reynolds number and twist ratio variation on the heat transfer and pressure drop characteristics. Heat transfer performance of modified twisted tapes and the decay of swirl downstream of the shortlength twisted tape are also reported through numerical studies. The effects of conductance in the tape and wall boundary conditions in the presence of full length twisted tape are investigated numerically. However a limited description of effect of secondary flow in terms of tangential and radial velocity and their individual contribution in heat transfer augmentation is reported in the literature. Tangential, radial and axial velocity distribution and the temperature distribution can be well observed with the help of numerical simulations. This may help in understanding the physics involved in the heat transfer enhancement and the design of much more effective tape inserts. Thus, the important objective of the present study is to understand the variation of axial, radial and tangential velocities over a particular section as a function of Reynolds number and twist ratio. The other objective of the present work is to understand the possible effect of these variations on temperature distribution and hence the heat transfer. The effect of Reynolds number and twist ratio on the Nusselt number and friction factor is also reported.

\section{Problem description}

The performance of the twisted tape is analysed using a test section as shown in figure 1. The twisted tape is fitted 
in the full length of the tube of diameter ' $D$ '. The effect of thickness of the tube and the contact resistance between tube and tape is neglected. The tape material is assumed to be aluminium. Although the tape conducts heat, thickness of the tape is assumed to be negligible, imposing zero temperature gradients along its cross section. This accounts for the tape fin effect in the heat transfer, suppressing the effect of tape thickness. The tape has a pitch of ' $H$ ' for $180^{\circ}$ rotation. The width of the tape is equal to the diameter of the tube. The tape is in contact with the tube over the entire length of the tube. When the twisted tape is inserted in a tube the orientation of the tape with respect to the tube is repeated after every ' $2 H$ ' distance in the axial direction, and the flow becomes periodically fully developed in the axial direction. Investigations are carried out for twist ratio $(H / D)$ $4,5,6,8,10$ and $\infty$ in the laminar region of flow regime at $100 \leq R e \leq 1000$.

The continuity, momentum and energy equations for three-dimensional models are employed. For steady state, constant density flow the Navier-Stokes $(\mathrm{N}-\mathrm{S})$ equations in Cartesian tensor notation can be written as follows.

Continuity equation:

$$
\frac{\partial}{\partial x_{i}}\left(\rho u_{i}\right)=0 .
$$

Momentum equation:

$$
\frac{\partial}{\partial x_{j}}\left(\rho u_{i} u_{j}\right)=-\frac{\partial p}{\partial x_{i}}+\frac{\partial}{\partial x_{j}}\left[\mu\left(\frac{\partial u_{i}}{\partial x_{j}}+\frac{\partial u_{j}}{\partial x_{i}}\right)\right] .
$$

Energy equation:

$$
\frac{\partial}{\partial x_{j}}\left(u_{j} \rho C_{p} T\right)=\frac{\partial}{\partial x_{j}}\left(k_{\text {eff }} \frac{\partial T}{\partial x_{j}}\right) .
$$

These equations are solved using a commercial solver. Second-order upwind schemes for pressure, momentum and energy equations are employed in the numerical model. The pressure-velocity coupling is handled by the SIMPLE algorithm. Solutions are iterated till wall temperature, tangential velocity and average fluid temperature over a cross section in the in the axial direction show a constant reading. Data in the form of axial, tangential, radial velocities, pressure drop and temperature at various locations are obtained. The unsteady state $\mathrm{N}-\mathrm{S}$ equations were used during a few preliminary simulations. However, it was noticed that the flow turns out to be a steady state flow. Hence, steady state $\mathrm{N}-\mathrm{S}$ equations are used for further simulations.

As the flow in a pipe with twisted tape inserts exhibits periodic nature in the axial direction $[19,20]$ the periodic

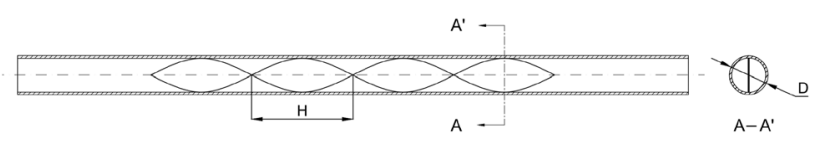

Figure 1. Geometry of twisted tape in a circular tube. boundary conditions are used at the inlet and outlet. Constant surface heat flux (UHF) is enforced on the tube wall. The tape is assumed to be coupled to the wall with no slip boundary condition on the surface. No slip condition is imposed on the inner diameter of the tube wall. The thickness of the tube and tape and the contact resistance between tube and tape are neglected.

The grid used in the present analysis is shown in figure 2 . The domain is discretized into hexahedral cells. Water is used as a working fluid. The contact resistance between tube and tape surface is neglected. The physical properties of fluid and tape are assumed to be constant and the fluid is incompressible. The flow and heat transfer are in the steady state with no viscous dissipation.

Three different grids of approximate size in multiples of $X, 2 X$ and $4 X$ were selected and evaluated at $\operatorname{Re}=500$, to identify the appropriate grid size for the different twist ratio cases. The results of the independent grid evaluations are listed in table 1 , and the maximum variation in either the Nusselt number or the friction factor was observed to be within 5\% among the grids. However, close agreement is observed between grid $2 X$ and $4 X$, and hence grid of size $2 X$ is selected for all simulations.

The data obtained numerically are validated with the available experimental data by Manglik and Bergles [4] for pressure drop in terms of friction factor analysis and data by Hong and Bergels [2] for heat transfer in terms of Nusselt number as a function of Reynolds number.

The friction factors result shows good agreement with the correlation based on experimental data reported by Manglik and Bergles [4]; the maximum relative deviation is about $\pm 10 \%$ (see figure 3 ).

Compared to the correlation, it is noted that the majority of numerical results show good agreement within $\pm 15 \%$, and the maximum relative deviation between present results and the correlation is about $27 \%$. The fair agreement of some of the numerical results may be attributed to the conditions during the experimental procedure performed by Hong and Bergles [2]. The tape during the experiments performed by Hong and Bergles [2] was insulated from the tube. Due to the absence of the tape fin effect, the Nusselt number is low. The Reynolds number calculated by Hong and Bergles [2] is based on the swirl velocity, which is normally higher than the velocity of the fluid in the empty tube. For calculation of swirl axial velocity, the correction in the area due to insertion of twisted tape is accounted for by Hong and Bergles [2]. In the present case, the Reynolds number is evaluated using the area of the plain tube. The correlation given shows good agreement for fluid with $\operatorname{Pr}=100$ [21]. However, in the present case, working fluid is water with $\operatorname{Pr}=6.99$.

The available correlations for friction factor and Nusselt number are based on curve fitting method or by semi-empirical theoretical analysis. The correlations for the friction factor and Nusselt number based on numerical data are 


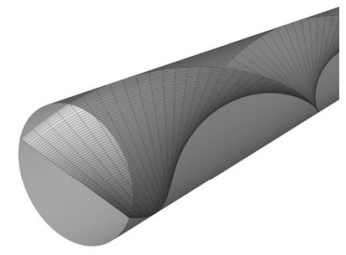

(a)

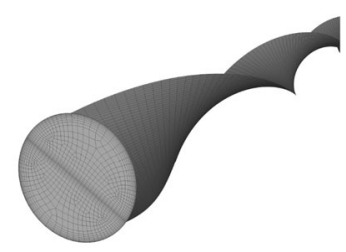

(b)
Figure 2. Grid used for computations in the present analysis showing (a) tube tape arrangement and (b) tape and inlet arrangement.

Table 1. Results of the different grids tested.

\begin{tabular}{cccc}
\hline$H / D$ & Grid size & $f$ & $\mathrm{Nu}$ \\
\hline 4 & 117996 & 0.4443 & 16.07 \\
& 227950 & 0.4425 & 15.83 \\
& 406496 & 0.4413 & 15.68 \\
5 & 131228 & 0.4111 & 15.64 \\
& 258868 & 0.4086 & 14.72 \\
& 445162 & 0.4082 & 14.70 \\
6 & 165332 & 0.388947 & 14.17 \\
& 273492 & 0.388222 & 13.61 \\
& 382408 & 0.392888 & 13.54 \\
8 & 167314 & 0.36847 & 11.77 \\
& 359000 & 0.367957 & 11.6 \\
10 & 499652 & 0.368398 & 11.55 \\
& 195756 & 0.357954 & 10.92 \\
& 373646 & 0.35711 & 10.98 \\
& 540516 & 0.358321 & 10.9 \\
\hline
\end{tabular}

developed using non-linear regression analysis and are given by Eqs. (4) and (5):

$$
\begin{gathered}
f=115 \operatorname{Re}^{-0.92}\left(1+\left(\frac{H}{D}\right)^{-2.5}\right), \\
\mathrm{Nu}=6.1\left[1+0.005484 \operatorname{Pr}^{0.7}\left(\frac{\pi}{(\pi-4 \delta)} \frac{\operatorname{Re}}{\left(\frac{H}{D}\right)}\right)^{1.15}\right]^{0.5} .
\end{gathered}
$$

Comparisons of the present data to those calculated by the present correlations for friction factor (Eq. (4)) and Nusselt number (Eq. (5)) are portrayed in figure 4a and b, respectively. It can be observed that the majority of the heat transfer and friction factor data fall within $\pm 10 \%$ for the present correlations. Equations (4) and (5) predict the friction factor and Nusselt number data within $\pm 15 \%$, and Eq. (5) predicts Nusselt number data within $\pm 20 \%$ agreement.

\section{Effect of Reynolds number and twist ratio}

Insertion of the twisted tape alters the flow profile in a tube. The heat transfer augmentation using twisted tape is found to be a function of twist ratio and Reynolds number.

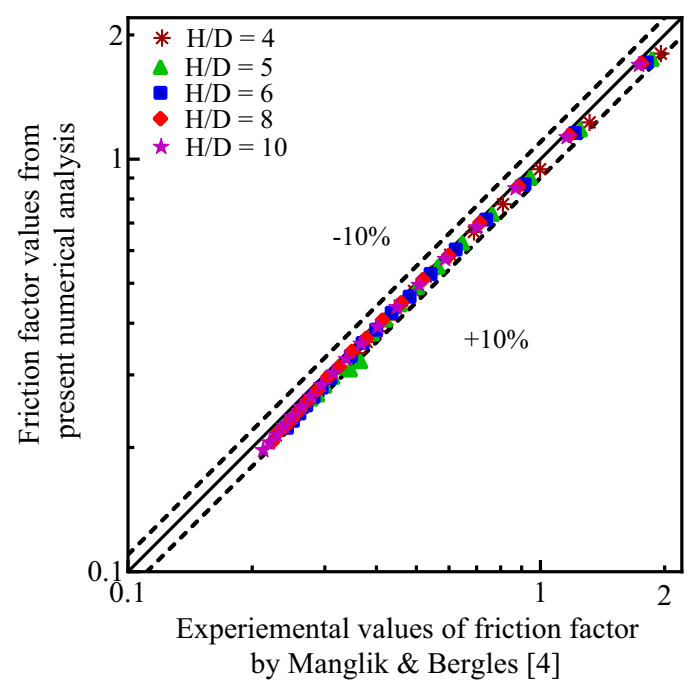

(a)

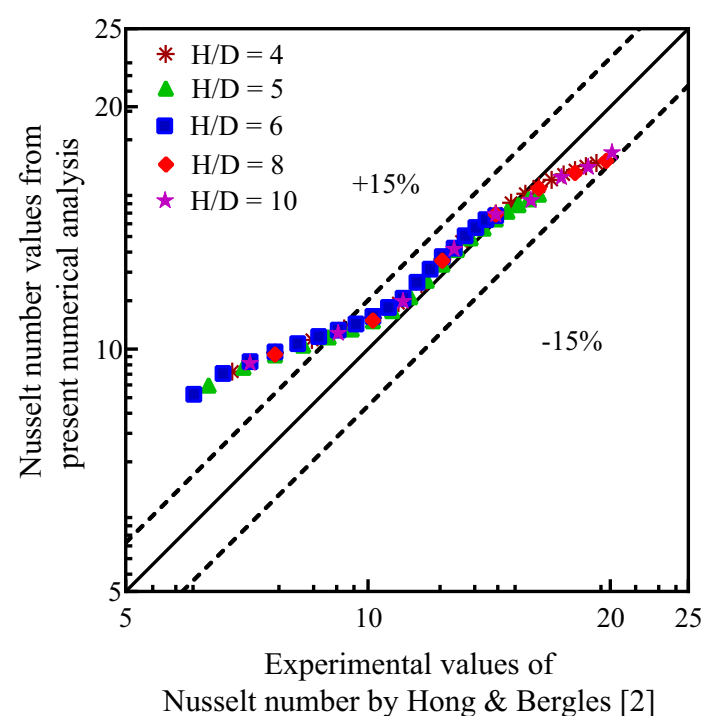

(b)

Figure 3. Comparison of (a) friction factor and (b) Nusselt number obtained from present study and experimental data of Manglik and Bergles [4] and Hong and Bergles [2].

Twisted tape imparts tangential and radial velocity components to the flow [1]. The fluid temperature profile is also altered by the insertion of twisted tape [3]. The heat transfer augmentation depends on the absolute vorticity flux [19]. The effects of twist ratio and the Reynolds number on the distribution of axial, tangential and radial velocities, fluid temperature, pressure drop and heat transfer are presented in this section.

\subsection{Axial velocity}

Twisted tape converts the circular tube into two helical compartments. The flow takes place along the spiral path 


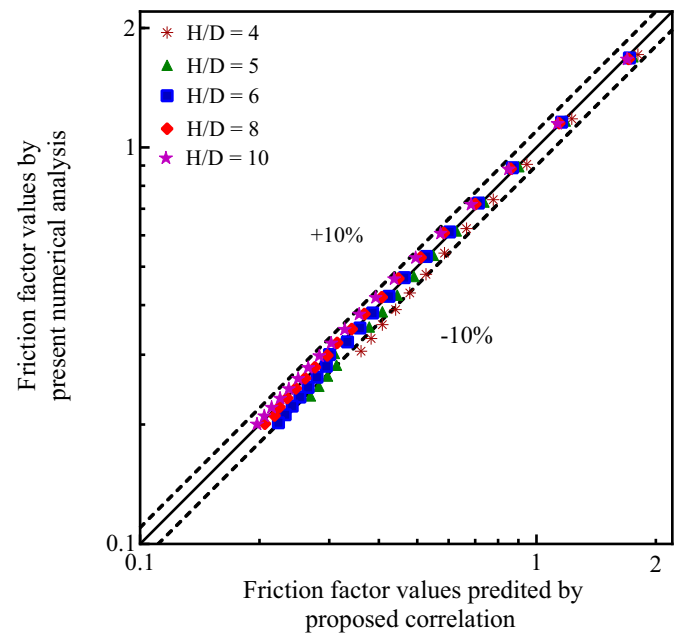

(a)

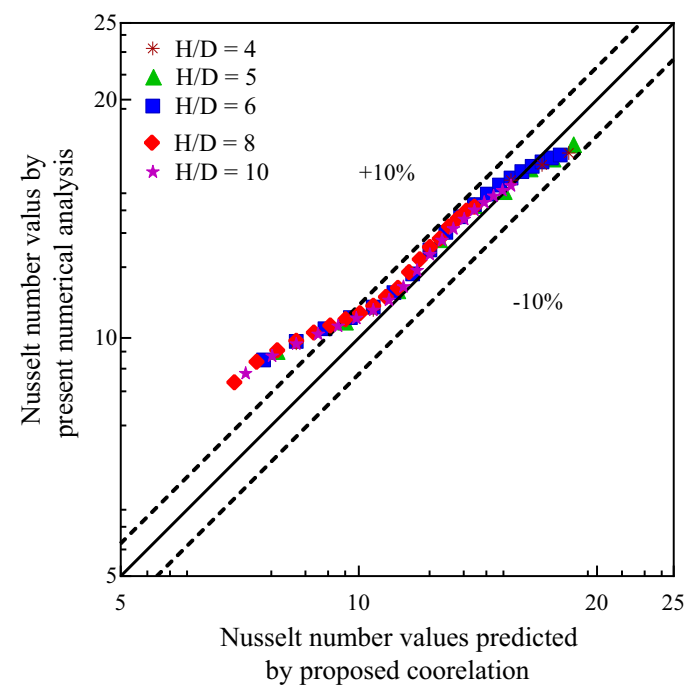

(b)

Figure 4. Comparison of the values obtained by numerical analysis and values predicted by proposed correlation for (a) friction factor and (b) Nusselt number.

defined by the twist ratio in the tube. The Reynolds number is defined based on the axial velocity in the empty tube:

$$
\operatorname{Re}=\frac{V_{z, m} D \rho}{\mu}
$$

where $V_{z, m}$ is the mean velocity in the axial direction. Figure $5 \mathrm{a}$ and $\mathrm{b}$ shows the velocity contours for straight tape $(H / D=\infty)$ for $\operatorname{Re}=100$ and $\operatorname{Re}=1000$, respectively. The velocity profile remains the same for all Reynolds number considered here at $H / D=\infty$. The peak of the velocity is found to be at an angle of $\phi=\pi / 2$ to the tape surface and at the centre of the flow area. This is similar to the flow through an empty tube. The rise in friction factor due to insertion of the straight tape is mainly due to additional friction at the tape surface. Figure $5 \mathrm{c}-\mathrm{e}$ shows the contours of the axial velocity at $H / D=4$ and 10 for $\operatorname{Re}=100$ and 1000, which are two extreme Reynolds numbers and twist ratio in the present study. The axial velocity profile can be divided into two parts: the core helicoidal flow and boundary layer flow. The axial velocity remains constant in the helicoidal region. Gradients of velocity are observed outside the helicoidal region. The magnitude of the maximum axial velocity is constant irrespective of the twist ratio at a particular Reynolds number. This indicates that the twist ratio does not alter the magnitude of the axial velocity. However, the location of the peak axial velocity shifts towards the tape surface. For tighter twist 4 and 5, this shift is found at lower Reynolds number as reported by Date [3]. This can be attributed to the high amount of swirl in the flow for small twist ratios. At tighter twists, peak axial velocity shifts towards tape surface with increasing Reynolds number. This gives rise to high velocity gradients near tape surface. These gradients disturb the thermal boundary layer over the tape surface and hence higher heat transfer from tape to the fluid is achieved.

Figure 6 shows the axial velocity at an angle of $\phi=\pi / 2$ to the tape surface, for different twist ratios at various values of Reynolds number. The axial velocity profile remains unchanged for all twist ratios at $\mathrm{Re}=100$. The axial velocity profile is parabolic and a small effect of twist is seen at $\mathrm{Re}=100$ for all twist ratios. This shows that the effect of twist is low at the low Reynolds number. High velocity gradients near the tube surface are observed even at the small Reynolds number for tighter twists. The higher velocity gradients at the tube wall reduce the boundary layer thickness at the wall and hence heat transfer rate increases. The mean axial velocity magnitude for the tube with twisted tape is greater than that for the empty tube for all twist ratios and Reynolds numbers. This velocity is termed as swirl velocity, which was earlier reported by Hong [21] and Manglik and Bergles [4]. Besides decrease in the flow cross-sectional area, the longer flow path in the flow direction and helical nature of the flow are the reasons for this rise in the axial velocity magnitude.

\subsection{Secondary flow}

Secondary flow is a flow in the direction normal to the main flow. This suggests the existence of velocity components other than the main velocity at a cross section normal to the flow. Further, for flow in the tube with insert the tangential and radial components of the velocity are observed on a cross section normal to the flow direction. Although the solution of the problem is obtained using a Cartesian coordinate system the tangential and radial velocity at a given location is obtained by resolving the vector velocity at the given location along tangential and radial directions. Figure 7 shows the streamlines of velocity on a plane normal to the flow direction for twist ratio 4 and twist ratio 


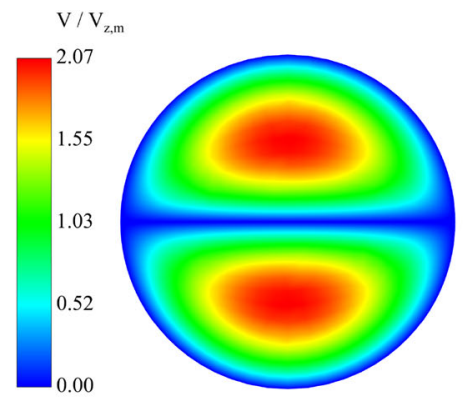

(a)

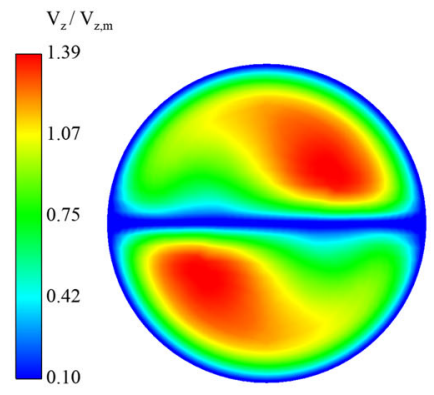

(d)

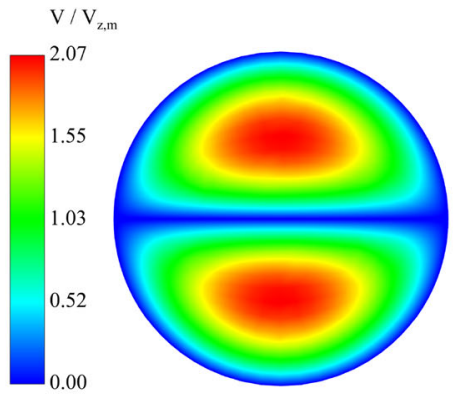

(b)

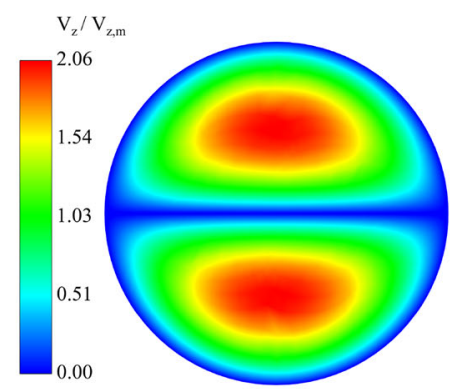

(e)

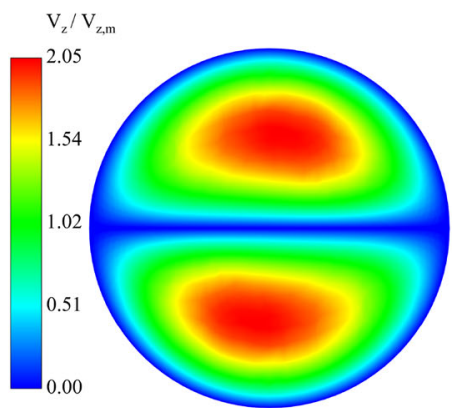

(c)

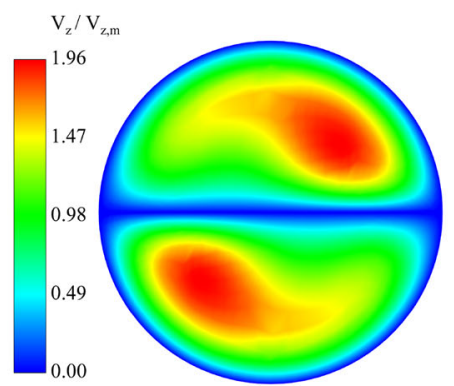

(f)

Figure 5. Axial velocity contours for the fully developed flow at (a) $H / D=\infty$ and $\operatorname{Re}=100$, (b) $H / D=\infty$ and $\operatorname{Re}=1000,(\mathbf{c}) H /$ $D=4$ and $\operatorname{Re}=100,(\mathbf{d}) H / D=4$ and $\operatorname{Re}=1000,(\mathbf{e}) H / D=10$ and $\operatorname{Re}=100$ and (f) $H / D=10$ and $\operatorname{Re}=1000$.

10. The swirling nature of the flow is evident from the nature of the streamlines. The amount of swirl at $\mathrm{Re}=100$ for $H / D=4$ is more than the swirl for $H / D=10$. The similar nature of the streamlines at lower Reynolds number for all twist ratios suggests low intensity secondary flow at low Reynolds number for all twist ratios. The higher swirl at tighter twist ratio at given Reynolds number indicates that the intensity of secondary flow primarily depends on the twist ratio.

\subsection{Tangential velocity}

Insertion of the twisted tape imparts tangential velocity component to the flow. Figure 8 shows the contours of tangential velocity at various Reynolds numbers for different twist ratios. The magnitude of the tangential velocity at lower values of twist ratio is higher. The maximum normalized tangential velocity shows little variation over the Reynolds number range studied for small twist ratios. For $H / D=4$, tangential velocity varies against the Reynolds number; however, for $H / D=10$ it remains constant. This leads to a rise in heat transfer with respect to Reynolds number for smaller twist ratios. The Nusselt number increases approximately twice when Re changes from 100 to 700 at $H / D=4$. This rise is only 1.4 times for $H /$ $D=10$. The magnitude of tangential velocity is more for tighter twist ratios. Tighter twist increases the swirl number
'Sw' defined by Manglik and Bergles [4], which is an indicator of secondary flow. The tighter twist makes the flow follow a spiral path and hence the magnitude of the tangential component increases. This indicates that the severity of the twist is the governing parameter of the tangential velocity. Heat transfer enhancement using twisted tape is strongly dependent on the intensity of secondary flows [19]. At small twist ratio, the intensity of secondary flow is higher than the intensity for higher twist ratios. Therefore, high heat transfer rate is found for lower twist ratios. The dominance of the tangential velocity in the flow field increases with Reynolds number. For $\mathrm{Re}>400$ the maximum tangential velocity is found to be over almost $50 \%$ of the flow area, and the heat transfer augmentation is due to displacement of the thermal boundary layer in this region.

Figure 9 shows the plots of tangential velocity obtained for different twist ratios at an angle of $\phi=\pi / 2$ to the tape surface at various Reynolds numbers. The tangential velocity at $\operatorname{Re}=100$ remains the same for all twist ratios. However, with increasing Reynolds number the higher tangential velocity shifts towards the tube surface. This shift is very similar to that of the axial velocity. The higher tangential velocity at the tube surface sweeps the thermal boundary layer at the tube surface. The local Nusselt number increases due to swiping of the thermal boundary layer and heat transfer increases. Higher tangential velocity gradients and greater magnitude of the tangential velocity 


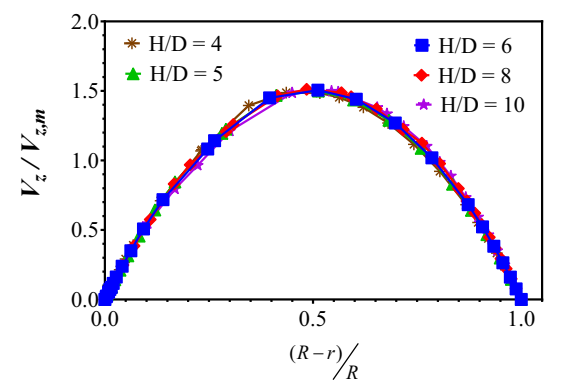

(a)

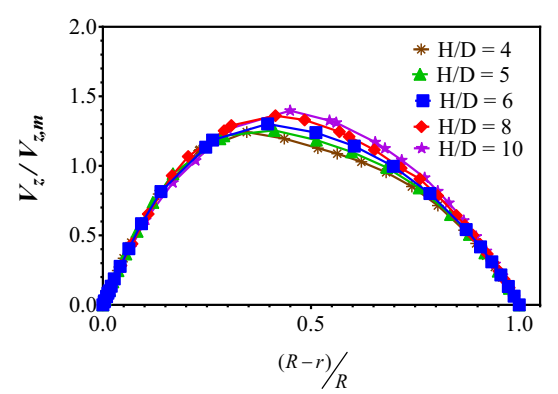

(d)

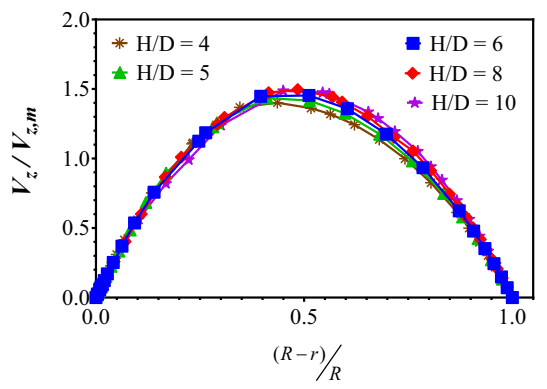

(b)

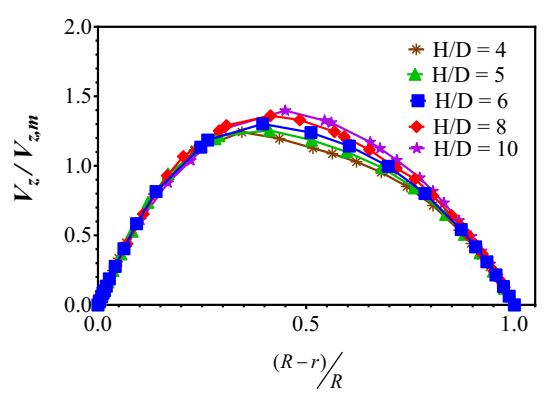

(e)

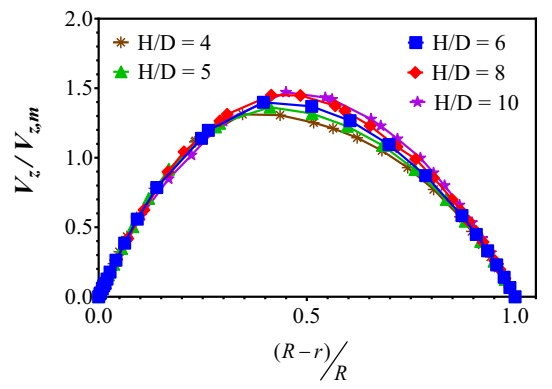

(c)

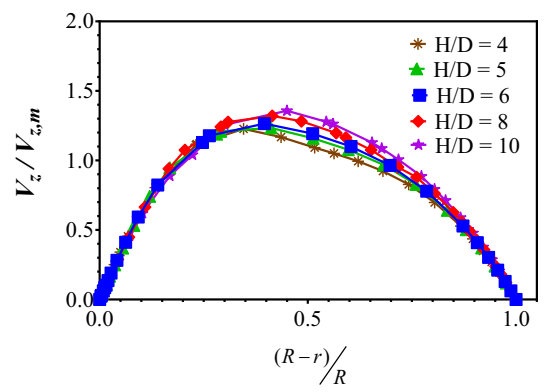

(f)

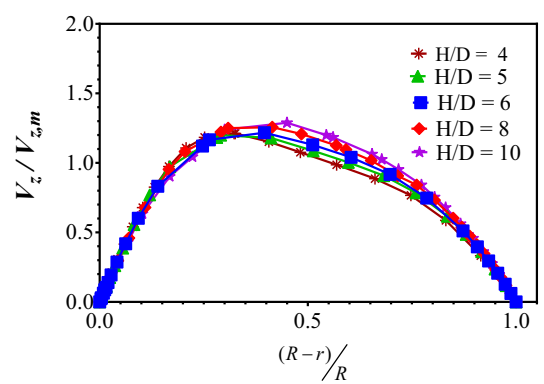

(g)

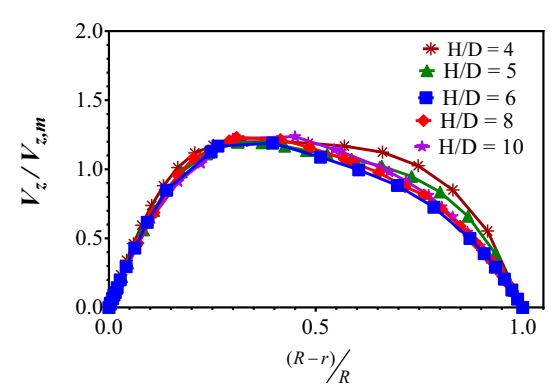

(h)

Figure 6. Velocity profile plotted at $\phi=\pi / 2$ at (a) $\operatorname{Re}=100,(\mathbf{b}) \operatorname{Re}=200,(\mathbf{c}) \operatorname{Re}=300,(\mathbf{d}) \operatorname{Re}=400,(\mathbf{e}) \operatorname{Re}=500$, (f) $\operatorname{Re}=600,(\mathrm{~g}) \mathrm{Re}=800$ and (h) $\mathrm{Re}=1000$ for different values of twist ratio.

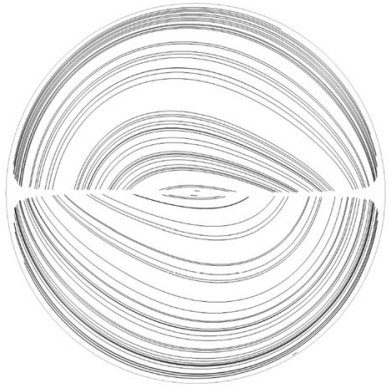

(a)

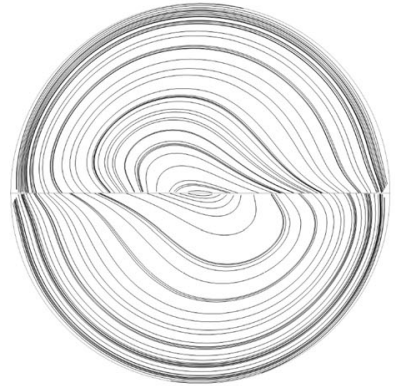

(b)

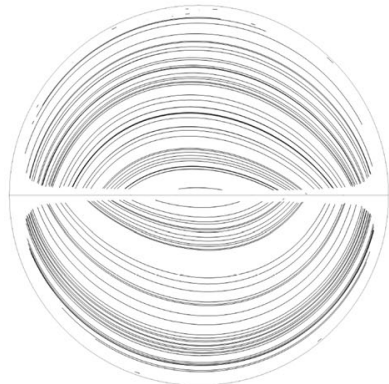

(c)

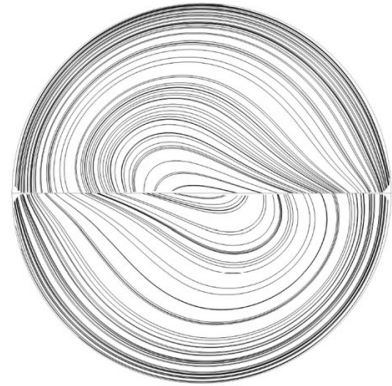

(d)

Figure 7. Streamlines of the velocity on a plane normal to the flow direction at (a) $H / D=4$ and $\operatorname{Re}=100$, (b) $H / D=4$ and $\operatorname{Re}=1000,(\mathbf{c}) H / D=10$ and $\operatorname{Re}=100$ and $(\mathbf{d}) H / D=10$ and $\operatorname{Re}=1000$.

are observed for lower twists. The higher tangential velocity at lower twists increases the heat transfer rate and also increases the pressure drop in the flow due to high swirling nature of the flow. The magnitude of tangential velocity decreases with increasing twist ratio for a given Reynolds number. It can be observed that for $H / D=10$, 


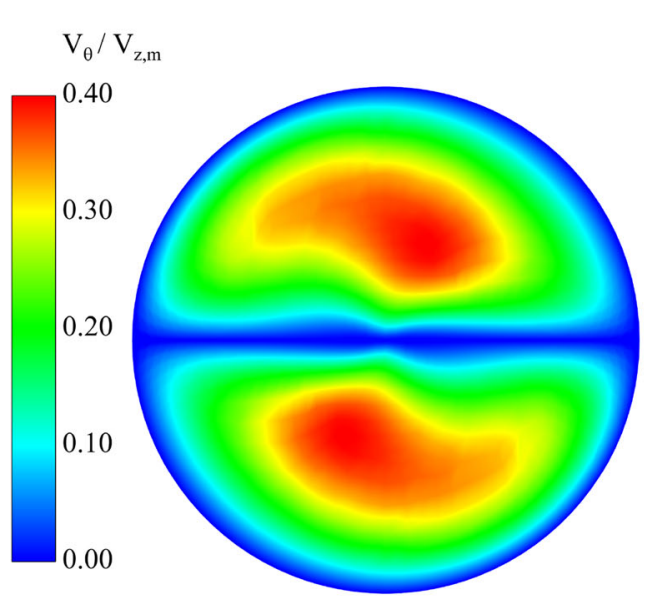

(a)

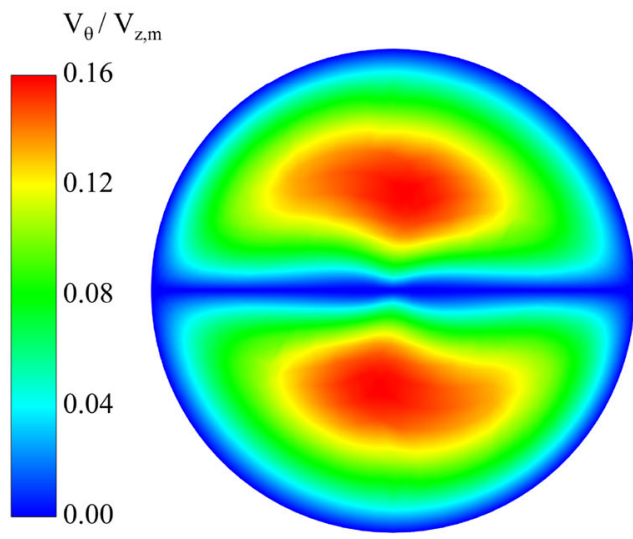

(c)

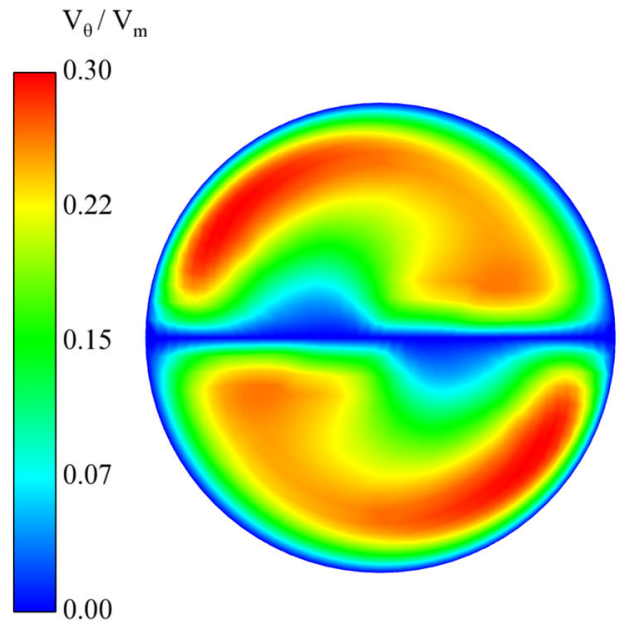

(b)

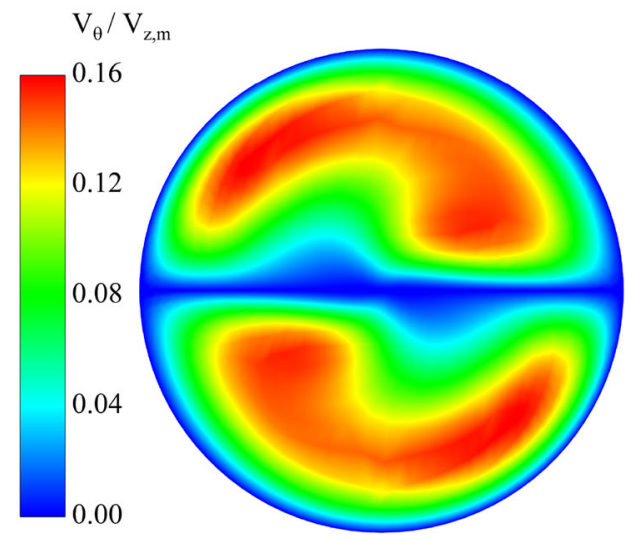

(d)

Figure 8. Tangential velocity contours for the fully developed flow at (a) $H / D=4$ and $\operatorname{Re}=100,(\mathbf{b}) H / D=4$ and $\operatorname{Re}=1000,(\mathbf{c}) H /$ $D=10$ and $\operatorname{Re}=100$ and $(\mathbf{d}) H / D=10$ and $\operatorname{Re}=1000$.

the shift of peak of tangential velocity changes after $\mathrm{Re}$ $\geq 700$, indicating the lower dominance of tangential velocity in the flow field due to higher twist ratio and hence a lower heat transfer rate is observed for $H / D=10$ as compared with $H / D<10$. A significant difference in the tangential velocity profile at $\mathrm{Re}=1000$ is observed in figure $9 \mathrm{~h}$ for $H / D=4$. This may be attributed to the onset of turbulence. This is also reflected in axial and radial velocity profiles. However, further analysis for this is required.

\subsection{Radial velocity}

Insertion of twisted tape also imparts radial velocity to the flow. The radial velocity is responsible for the cross-flow mixing. Figure 10 shows the contours of the radial velocity at different twist ratios and Reynolds numbers. It is observed that the maximum radial velocity component is lesser in magnitude than that of tangential velocity. Higher radial velocity is observed at lower twists. This is the direct result of high rotational movement of the fluid particles at lower twists and hence, more centrifugal action is experienced. The swirl in the flow decreases with increasing twist ratio and hence the radial and tangential velocity components also decrease. Negative radial velocity is observed near the tape in the direction of flow. The flow near the tape continuously changes direction with the tape. Less centrifugal action, the dominance of boundary layer and direction change decrease the magnitude of the radial velocity in the near tape area.

Figure 11 shows the variation of radial velocity for different twist ratios at an angle of $\phi=\pi / 2$ to the tape surface at various Reynolds numbers. At smaller twist ratio the 


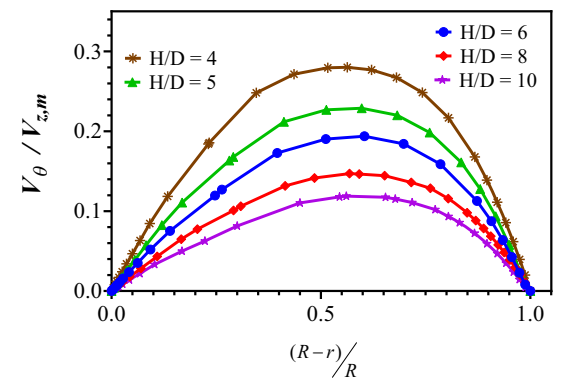

(a)

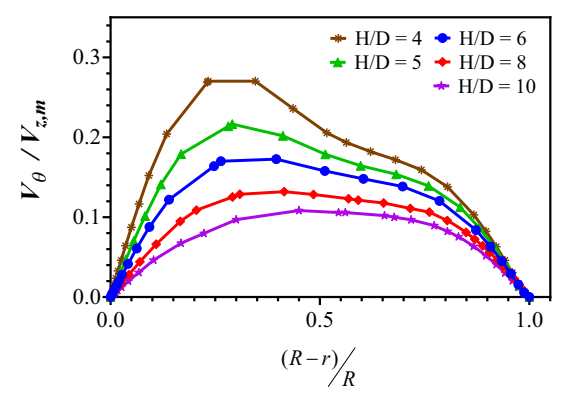

(d)

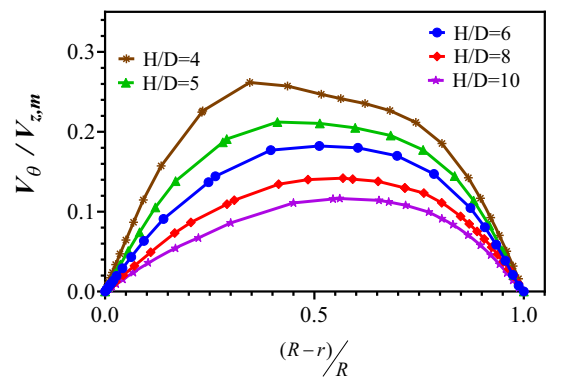

(b)

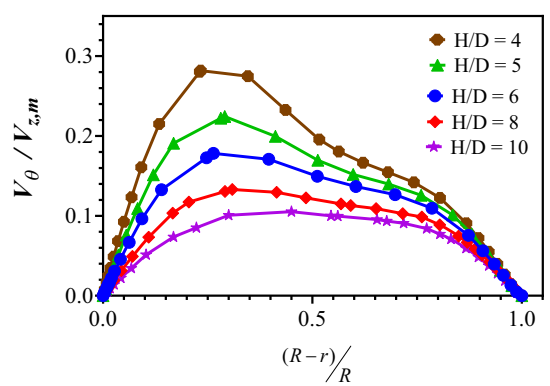

(e)

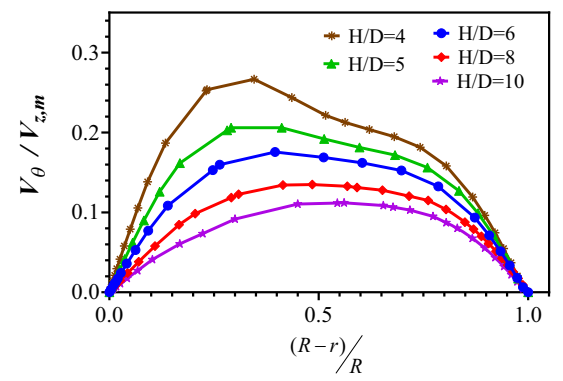

(c)

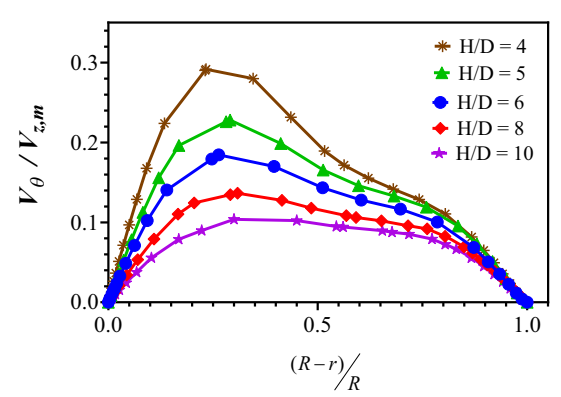

(f)

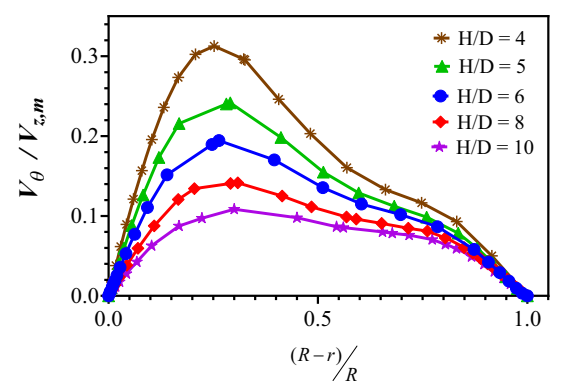

(g)

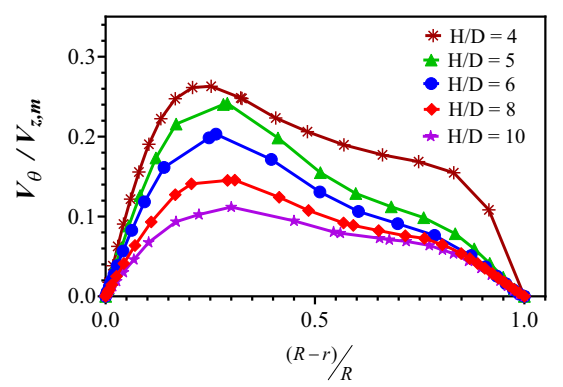

(h)

Figure 9. Tangential velocity profile plotted at $\phi=\pi / 2$ at $(\mathbf{a}) \operatorname{Re}=100,(\mathbf{b}) \operatorname{Re}=200,(\mathbf{c}) \operatorname{Re}=300,(\mathbf{d}) \operatorname{Re}=400,(\mathbf{e}) \operatorname{Re}=500$, (f) $\operatorname{Re}=600,(\mathrm{~g}) \mathrm{Re}=800$ and (h) $\operatorname{Re}=1000$ for different values of twist ratio.

radial velocity is higher as expected due to higher swirl. The radial velocity causes mixing of hot and cold fluid in the flow. The heat from the tape is transferred to the core flow due to radial velocity. Though the amount of radial velocity is very small as compared with tangential component of the velocity, it contributes in increasing the bulk mean temperature of the fluid. Nusselt number is inversely proportional to the wall and bulk mean temperature difference. Thus, the radial velocity increases the Nusselt number of the flow.

\subsection{Effect of Reynolds number and twist ratio on fluid temperature}

The twisted tape inserts increase the heat transfer rate from the tube wall to the fluid. The nature of the flow and temperature distribution inside the tube is altered by the twisted tape insert. Figure 12a and b shows the temperature contours for straight tape $(H / D=\infty)$ at $\operatorname{Re}=100$ and $\operatorname{Re}=1000$, respectively. The temperature at the core of the flow is the same as the inlet temperature of the fluid. The temperature around tube tape contact area is the highest. The conduction in the tape increases the temperature of the fluid in this area. The constant Nusselt number for straight tape case indicates that the thermal boundary condition remains unchanged. The temperature profile changes with the effect of twist ratio. Figure 12c-f shows the variation of temperature with twist ratio and Reynolds number. The temperature at the core of the flow remains unaffected by the wall effects at $\operatorname{Re}=100$ for all values of twist ratios. The effect of twist is not seen at lower Reynolds numbers and the flow field remains unaffected by the presence of twisted tape, so the temperature distribution also remains 


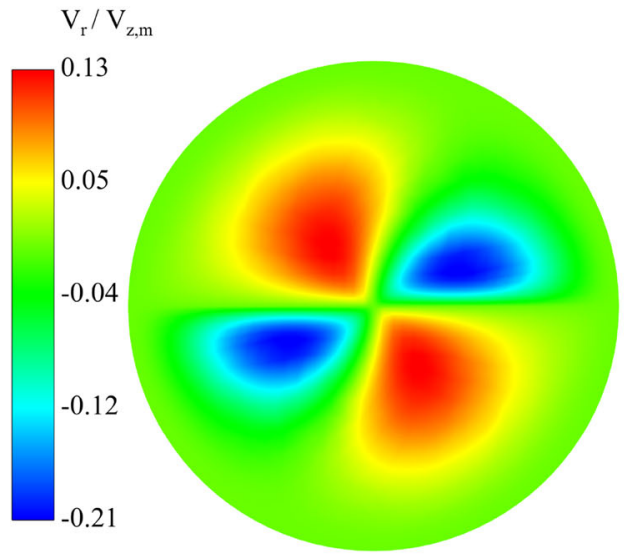

(a)

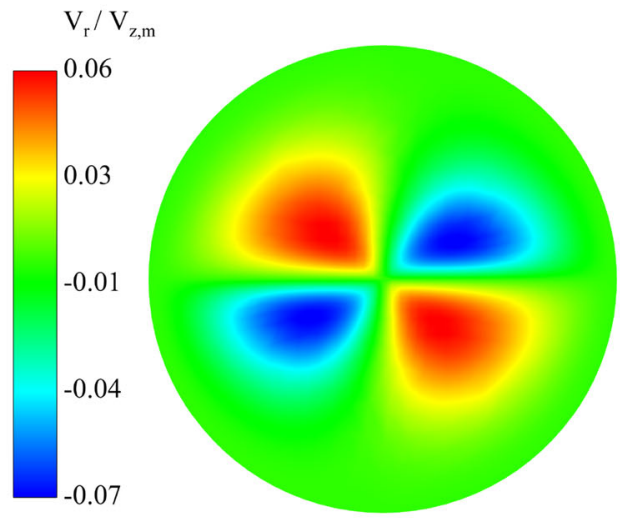

(c)

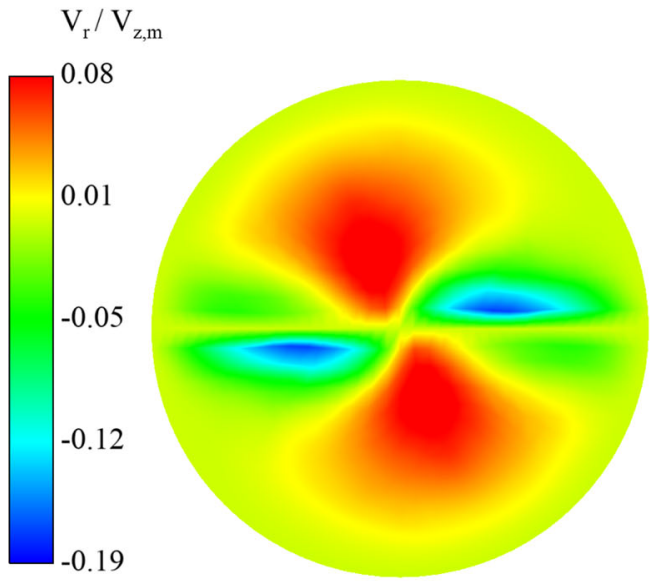

(b)

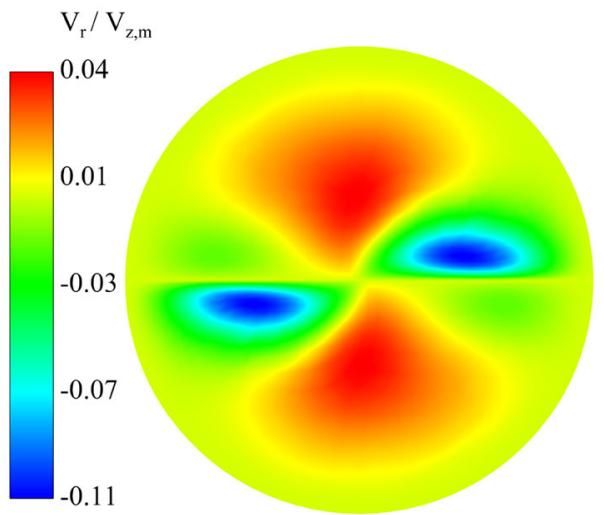

(d)

Figure 10. Radial velocity contours for fully developed flow at (a) $H / D=4$ and $\operatorname{Re}=100$, (b) $H / D=4$ and $\operatorname{Re}=1000$, (c) $H /$ $D=10$ and $\operatorname{Re}=100$ and $(\mathbf{d}) H / D=10$ and $\operatorname{Re}=1000$.

unaffected. The highest fluid temperature is found at the tube tape contact area. This can be attributed to the tape fin effect. Heat is transferred from the wall to the tape, and then from the tape to the wall in this region. Heat transfer to the fluid is found to be more with increasing Reynolds number. This is the direct result of the higher intensity of tangential and radial velocity.

Figure 13 shows the effect of twist ratio on the nondimensional temperature distribution in the fluid. Similar nature of the graph for all twist ratios clearly indicates the small effect of twist at low Reynolds number. The temperature of the fluid near the wall is also lower than the wall temperature due to the thermal boundary layer. The low axial and tangential velocity allows the development of thermal boundary layer at low Reynolds number. The temperature at the tape surface is also lower than the average fluid temperature due to the formation of thermal boundary layer on the tape surface. Owing to the highly swirling nature of the flow for $H / D=4$, the fluid temperature near the pipe wall is almost uniform and same as the average wall temperature at $\mathrm{Re}=600$. On the contrary for higher twist ratio of $H / D=10$ at $\operatorname{Re}=1000$, the near-wall fluid temperature is not uniform. This shows the strong dependence of heat transfer enhancement on twist ratio. The core fluid temperature increases rapidly with Reynolds number for lower twist ratios due to higher intensity of secondary flows. Therefore the difference in the wall and fluid temperature decreases and Nusselt number at the tube surface increases with Reynolds number.

\section{Circumferential variation of Nusselt number}

The asymmetrical axial velocity profile, presence of tape and swirl induced by it alter the circumferential temperature distribution of the tube wall. Circumferential 


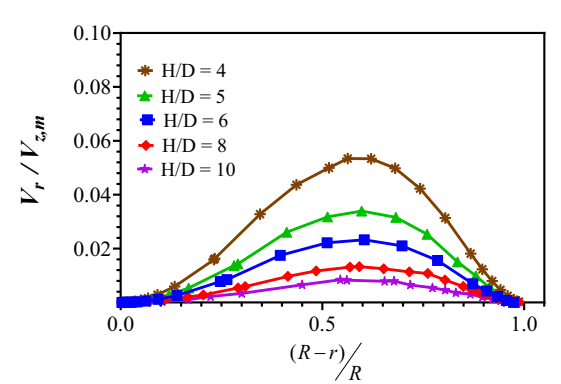

(a)

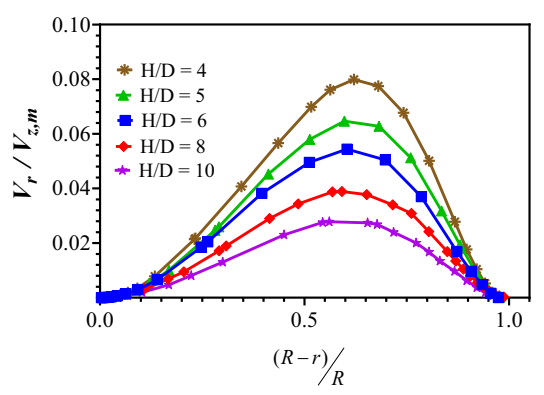

(d)

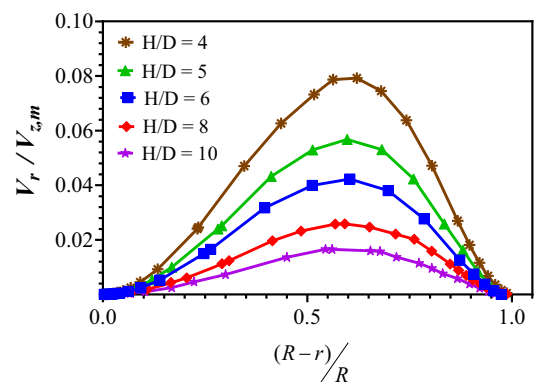

(b)

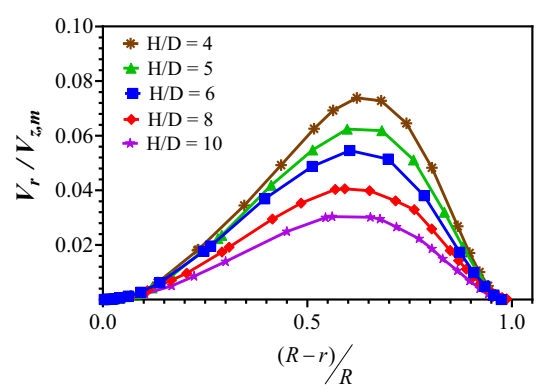

(e)

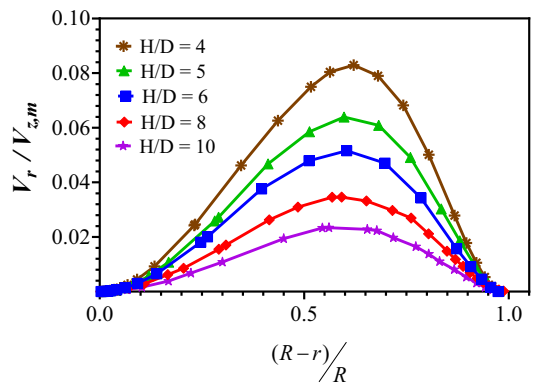

(c)

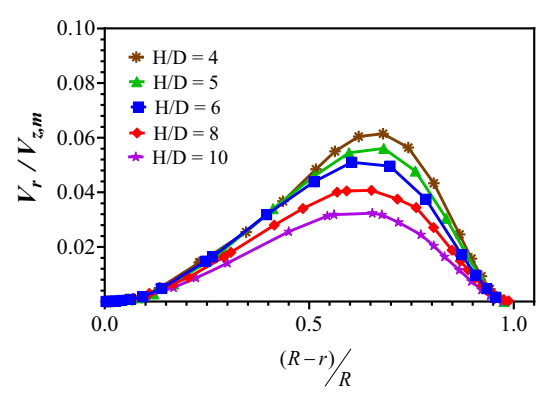

(f)

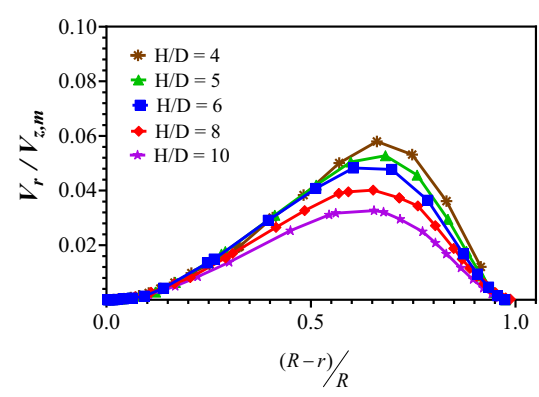

(g)

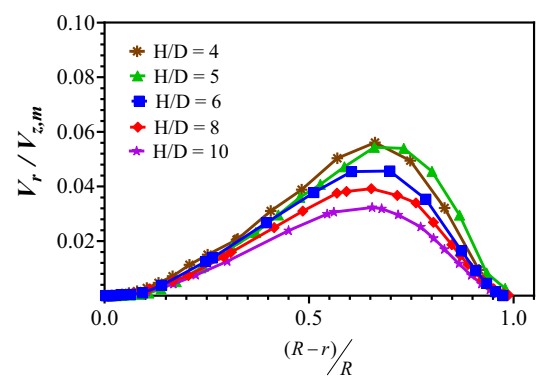

(h)

Figure 11. Radial velocity profile plotted at $\phi=\pi / 2$ at (a) $\operatorname{Re}=100$, (b) $\operatorname{Re}=200,(\mathbf{c}) \operatorname{Re}=300,(\mathbf{d}) \operatorname{Re}=400,(\mathbf{e}) \operatorname{Re}=500$, (f) $\operatorname{Re}=600,(\mathrm{~g}) \mathrm{Re}=800$ and (h) $\mathrm{Re}=1000$ for different values of twist ratio.

variation of Nusselt number on the pipe wall is depicted in figure 14. Due to the lower intensity of secondary flow, no variation in the circumferential Nusselt number is observed as a function of twist ratio considered in the present study at $\mathrm{Re}=100$. The Peak Nusselt number is found to be near tube-tape contact area in the direction of the flow. Sudden change in the flow direction in this region intensifies the axial velocity and reduces the temperature gradient on the tape surface. Heat transfer from the tape to the fluid further increases Nusselt number. Inception of secondary flow with rise in Reynolds number increases the fluid mixing and Nusselt number. Magnitude of tangential velocity is the prime reason for reduction in temperature gradients at the tube wall. Spread of tangential velocity over flow cross section is more at tighter twist for a given Reynolds number. Therefore, a flatter temperature and Nusselt number profile on tube wall is observed at $\operatorname{Re}=500$ for $H / D=4$ as shown in figure 14b. Variation in Nusselt number tends to become flatter with decreasing twist ratio at a given Reynolds number. Steep gradients in the near tape region suggest the localized rise in tangential velocity and hence reduction in the temperature gradients, resulting in higher Nusselt number. At $\mathrm{Re}=1000$ the variation of Nusselt number over tube circumference is small for all twist ratios except 10. Figure $14 \mathrm{c}$ shows the steep gradients for $H / D=10$ near the tube tape contact area in the direction of flow. The lower gradients in the other region suggest meager effect of secondary flow. A higher twist ratio cannot build swirl even at higher Reynolds number; therefore, heat transfer augmentation is more near tape area in the opposite to the flow direction. 


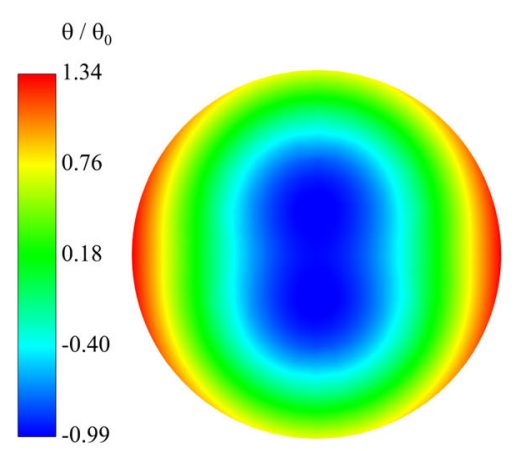

(a)

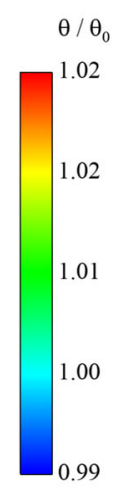

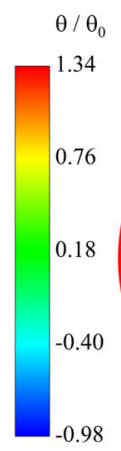

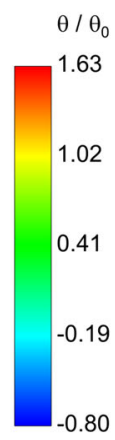

(b)
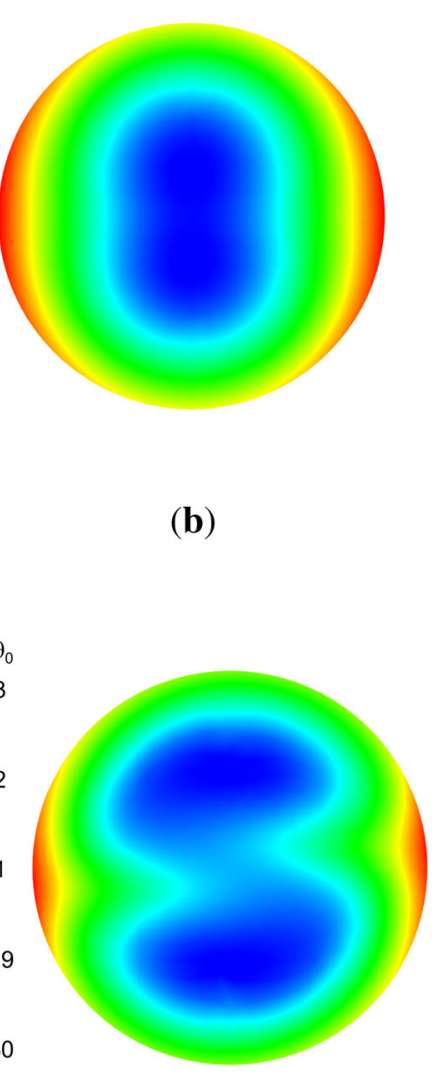

(e)

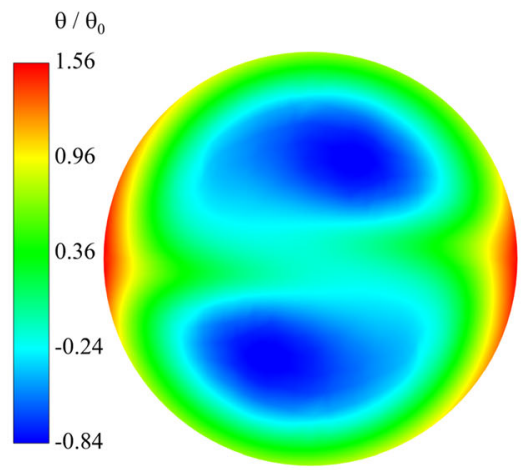

(c)

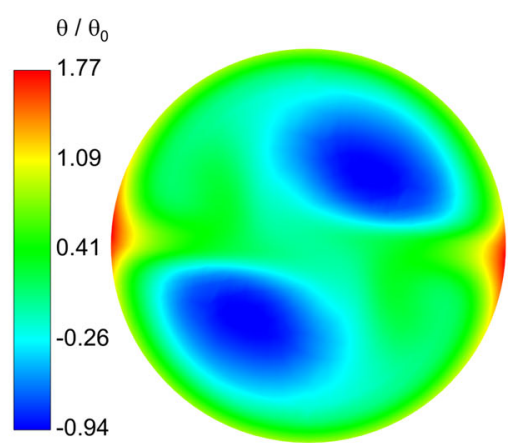

(f)

Figure 12. Temperature contours for the fully developed flow at (a) $H / D=\infty$ and $\operatorname{Re}=100,(\mathbf{b}) H / D=\infty$ and $\operatorname{Re}=1000,(\mathbf{c}) H /$ $D=4$ and $\operatorname{Re}=100,(\mathbf{d}) H / D=4$ and $\operatorname{Re}=1000,(\mathbf{e}) H / D=10$ and $\operatorname{Re}=100$ and (f) $H / D=10$ and $\operatorname{Re}=1000$.

\section{Discussion}

The twisted tape imparts swirl to the flow. Increased heat transfer and pressure drop are the results of the swirl imparted by twisted tape. A little heat transfer enhancement over that of straight tape at low Reynolds number for all twist ratios suggests the negligible effect of twist at low Reynolds number. In the presence of twisted tape at low Reynolds number, the dominant mode of momentum or heat transfer is diffusion. Therefore, at lower twist ratio, the heat transfer augmentation is less. The peak of axial velocity is at an angle of $\frac{\pi}{2}$ as observed at low Reynolds number. This indicates that the flow is similar to the flow through the plain tube. The additional heat transfer at low Reynolds number is due to the tape fin effect. Thus, the use of twisted tape is suggested at higher Reynolds number. With increase in Reynolds number the swirl in the flow gives rise to tangential and radial velocity components in the flow. The tangential component sweeps the thermal boundary layer at the tube wall and tape and hence heat transfer increases. The magnitude of tangential velocity increases with increasing Reynolds number and decreasing twist ratio. Hence, the heat transfer enhancement also increases with Reynolds number and decreasing twist ratio. The radial velocity, being very small, does not contribute significantly. It causes cross-flow mixing and increases the rate of convection in the radial direction. It also helps increase the bulk temperature of the fluid and decreases the difference between wall temperature and bulk mean temperature of the fluid, hence leading to a rise in the Nusselt number. The higher pressure drop associated with the use of twisted tape is a result of higher momentum dissipation at the tube wall due to secondary flow. However, the small variation in pressure drop that results with the twist ratio indicates that the velocity boundary layer does not alter significantly with the introduction of twisted tape. Thus, the heat transfer enhancement due to the use of twisted tape depends on the tangential and radial components of the velocity. Circumferential variation of Nusselt number reduces with the rise in Reynolds number and decreases with twist ratio due to asymmetric velocity profile and temperature gradients. 


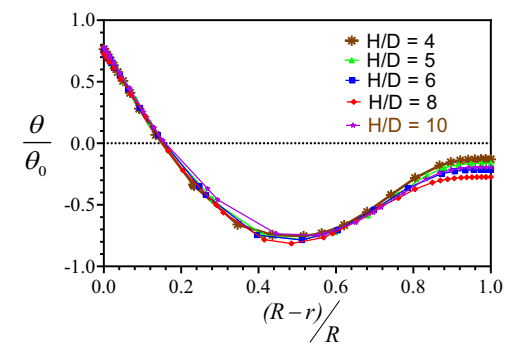

(a)

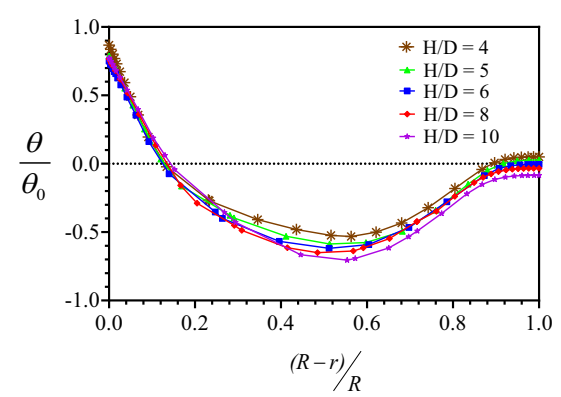

(d)

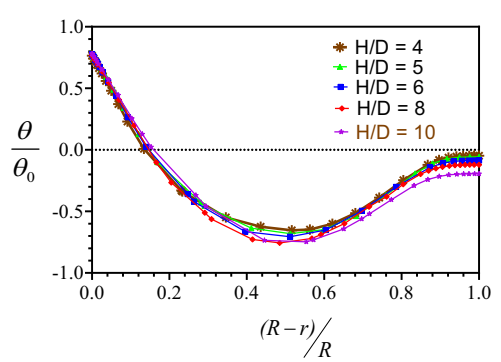

(b)

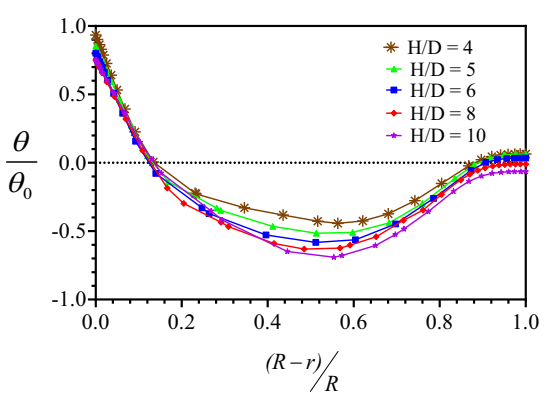

(e)

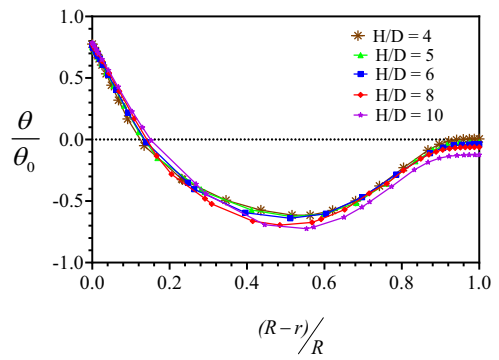

(c)

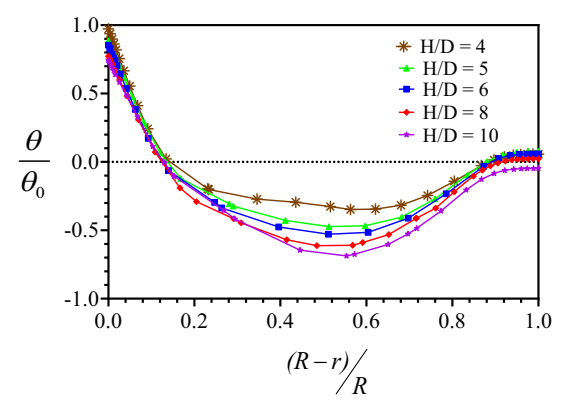

(f)

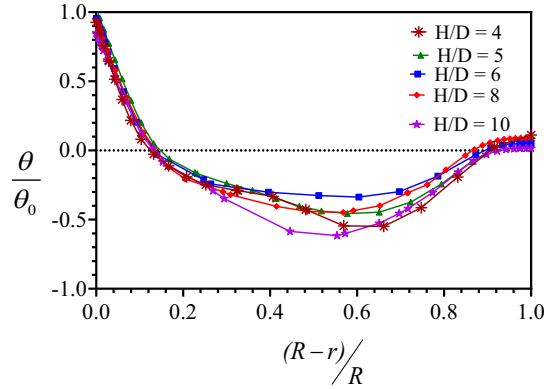

(g)

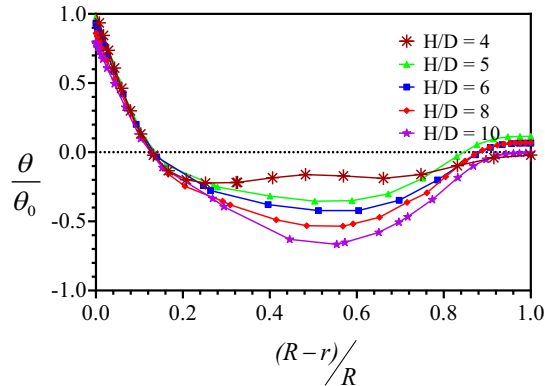

(h)

Figure 13. Fluid temperature profile plotted at $\phi=\pi / 2$ at (a) $\operatorname{Re}=100,(\mathbf{b}) \operatorname{Re}=200,(\mathbf{c}) \operatorname{Re}=300,(\mathbf{d}) \operatorname{Re}=400,(\mathbf{e}) \operatorname{Re}=500$, (f) $\mathrm{Re}=600,(\mathrm{~g}) \mathrm{Re}=800$ and (h) $\mathrm{Re}=1000$ for different values of twist ratio.

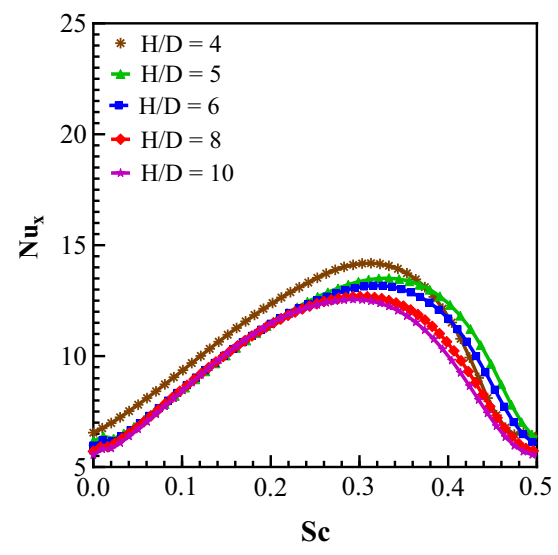

(a)

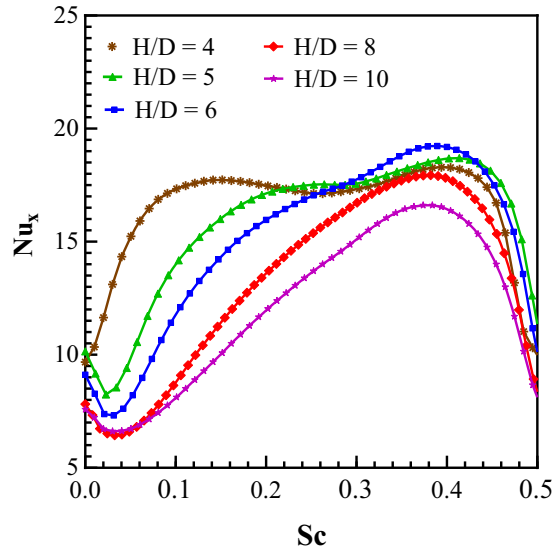

(b)

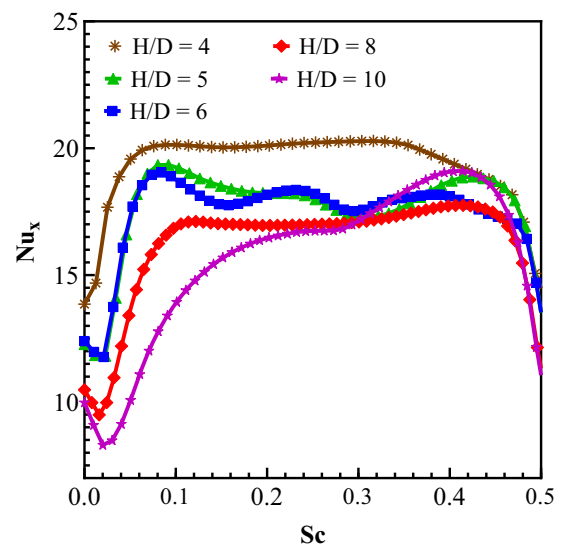

(c)

Figure 14. Variation of circumferential Nusselt number on tube surface measured clockwise from tape surface at (a) $\operatorname{Re}=100$, (b) $\operatorname{Re}=500$ and (c) $\operatorname{Re}=1000$. 


\section{Conclusion}

The effect of Reynolds number and twist ratio on the fluid flow and heat transfer in a tube with twisted tape insert is investigated numerically. The study concludes that the insertion of the twisted tape gives rise to tangential and radial velocity components, which can be considered as secondary flow in the system. The intensity of secondary flow increases with decreasing twist ratio. Tighter twist results in high swirling nature of the flow and hence heat transfer increases. Twisted tape alters the flow structure by shifting the peak of axial velocity towards the tube tape contact area with increasing Reynolds number at a given twist ratio. This shift alters the thermal boundary layer and heat transfer enhancement is achieved with increasing Reynolds number. The additional cost of twisted tape and increased pumping power may be justified at higher Reynolds number as heat transfer enhancement is low at low Reynolds number. Correlations for the prediction of Nusselt number and friction factor based on the present analysis are also proposed and are in good agreement with the experimental results from the literature .

The heat transfer and pressure drop primarily depend on the twist ratio and Reynolds number. The present work clarifies the phenomenon that leads to augmentation in heat transfer and pressure drop. A different viewpoint that gives a systematic understanding of the heat transfer due to combined effect of axial, tangential and radial convection and its effect on Nusselt number is offered here. The proposed mechanism of heat transfer is in tune with the results reported in the literature.

\section{Nomenclature}

\begin{tabular}{|c|c|}
\hline$D$ & diameter of the tube $(\mathrm{m})$ \\
\hline$f$ & friction factor \\
\hline$H$ & twist pitch length (m) \\
\hline$h$ & convective heat transfer coefficient $\left(\mathrm{W} /\left(\mathrm{m}^{2} \mathrm{~K}\right)\right)$ \\
\hline$k$ & thermal conductivity of the material $(\mathrm{W} /(\mathrm{mK}))$ \\
\hline$L$ & tube axial length $(\mathrm{m})$ \\
\hline $\mathrm{Nu}$ & Nusselt number \\
\hline$p$ & static pressure $\left(\mathrm{N} / \mathrm{m}^{2}\right)$ \\
\hline $\operatorname{Pr}$ & Prandtl number \\
\hline$q$ & heat flux $\left(\mathrm{W} / \mathrm{m}^{2}\right)$ \\
\hline$r$ & radial distance from the centre of the tube \\
\hline $\operatorname{Re}$ & Reynolds number \\
\hline $\mathrm{Sc}$ & $\begin{array}{l}\text { circumferential distance on the tube measured } \\
\text { clockwise from the tube tape contact point }\end{array}$ \\
\hline$T$ & temperature $(\mathrm{K})$ \\
\hline$u, v, w$ & $\begin{array}{l}\text { components of velocity vector in Cartesian } \\
\text { coordinates }(\mathrm{m} / \mathrm{s})\end{array}$ \\
\hline$V$ & velocity $(\mathrm{m} / \mathrm{s})$ \\
\hline$V_{r}, V_{\theta}, V_{z}$ & $\begin{array}{l}\text { components of velocity vector in cylindrical } \\
\text { coordinates }(\mathrm{m} / \mathrm{s})\end{array}$ \\
\hline$x, y, z$ & components of Cartesian coordinates (m) \\
\hline
\end{tabular}

\section{References}

[1] Smithberg E and Landis F 1964 Friction and forced convection heat-transfer characteristics in tubes with twisted tape swirl generators. J. Heat Transf. 86(1): 39

[2] Hong S W and Bergles A E 1976 Augmentation of laminar flow heat transfer in tubes by means of twisted-tape inserts. $J$. Heat Transf. 98(2): 251

[3] Date A W 1974 Prediction of fully-developed flow in a tube containing a twisted-tape. Int. J. Heat Mass Transf. 17(8): 845-859

[4] Manglik R M and Bergles A E 1993 Heat transfer and pressure drop correlations for twisted-tape inserts in isothermal tubes: part i-laminar flows. J. Heat Transf. 115(4): 881

[5] Agarwal S K and Raja Rao M 1996 Heat transfer augmentation for the flow of a viscous liquid in circular tubes using twisted tape inserts. Int. J. Heat Mass Transf. 39(17): $3547-3557$

[6] Wang L and Sundén B 2002 Performance comparison of some tube inserts. Int. J. Heat Mass Transf. 29(1): 45-56

[7] Chang S W, Yu K W and Lu M H 2005 Heat transfers in tubes fitted with single, twin, and triple twisted tapes. Exp. Heat Transf. 18(4): 279-294

[8] Klepper O H 1972 Heat transfer performance of short twisted tapes. Technical report, Office of Scientific and Technical Information (OSTI)

[9] Saha S K , Dutta A and Dhal S K 2001 Friction and heat transfer characteristics of laminar swirl flow through a circular tube fitted with regularly spaced twisted-tape elements. Int. J. Heat Mass Transf. 44(22): 4211-4223

[10] Saha S K, Gaitonde U N and Date A W 1990 Heat transfer and pressure drop characteristics of turbulent flow in a circular tube fitted with regularly spaced twisted-tape elements. Exp. Therm. Fluid Sci. 3(6): 632-640

[11] Saha S K and Dutta A 2001 Thermohydraulic study of laminar swirl flow through a circular tube fitted with twisted tapes. J. Heat Transf. 123(3): 417

[12] Eiamsa-ard S, Thianpong C and Promvonge P 2006 Experimental investigation of heat transfer and flow friction in a circular tube fitted with regularly spaced twisted tape elements. Int. Commun. Heat Mass Transf. 33(10): 1225-1233

[13] Saha S K and Date A W 1990 Numerical prediction of laminar flow and heat transfer characteristics in a tube fitted with regularly spaced twisted-tape elements. Int. J. Heat Fluid Flow 11(4): 346-354 
[14] Chiu Y W and Jang J Y 2009 3D numerical and experimental analysis for thermal-hydraulic characteristics of air flow inside a circular tube with different tube inserts. Appl. Therm. Eng. 29(2-3): 250-258

[15] Eiamsa-ard S, Wongcharee K and Sripattanapipat S 2009 3-D numerical simulation of swirling flow and convective heat transfer in a circular tube induced by means of loose-fit twisted tapes. Int. J. Heat Mass Transf. 36(9): 947-955

[16] Rahimi M, Shabanian S R and Alsairafi A A 2009 Experimental and CFD studies on heat transfer and friction factor characteristics of a tube equipped with modified twisted tape inserts. Chem. Eng. Process. Process Intensif. 48(3): 762-770

[17] Cui Y Z and Tian M C 2010 Three-dimensional numerical simulation of thermal-hydraulic performance of a circular tube with edgefold-twisted-tape inserts. J. Hydrodyn. Ser. B 22(5): 662-670

[18] Guo J, Fan A, Zhang X and Liu W 2011 A numerical study on heat transfer and friction factor characteristics of laminar flow in a circular tube fitted with centre-cleared twisted tape. Int. J. Therm. Sci. 50(7): 1263-1270

[19] Lin Z M and Wang L B 2009 Convective heat transfer enhancement in a circular tube using twisted tape. J. Heat Transf. 131(8): 081901

[20] Ray S and Date A W 2001 Laminar flow and heat transfer through square duct with twisted tape insert. Int. J. Heat Fluid Flow 22(4): 460-472

[21] Hong S W 1974 Laminar flow heat transfer in ordinary and augmented tube. PhD thesis, Iowa State University, Ann Arbor 